\title{
Synergistic Photocatalytic-adsorption Removal of Basic Magenta Effect of AgZnO/polyoxometalates Nanocomposite
}

\section{Heyun Tian}

Henan University

Jie Luo

Henan University

Ke Zhang

Henan University

Chenguang Ma

Henan University

Yiyi Qi

Henan University

Shixia Zhan

Henan University

HongLing Liu ( $\nabla$ hlliu@henu.edu.cn )

Henan University https://orcid.org/0000-0002-8005-8477

Mingxue Li

Henan University

\section{Research Article}

Keywords: AgZnO/polyoxometalates, nanocomposites, photocatalytic囚adsorbention, basic magenta removal

Posted Date: May 18th, 2021

DOI: https://doi.org/10.21203/rs.3.rs-518018/v1

License: (c) (i) This work is licensed under a Creative Commons Attribution 4.0 International License. Read Full License 


\section{Abstract}

The bifunctional photocatalytic-adsorbent AgZnO/polyoxometalates (AgZnO/POMs) nanocomposites were synthesized by combining AgZnO hybrid nanoparticles and polyoxometalates $\left[\mathrm{Cu}(\mathrm{L})_{2}\left(\mathrm{H}_{2} \mathrm{O}\right)\right] \mathrm{H}_{2}\left[\mathrm{Cu}(\mathrm{L})_{2}\left(\mathrm{P}_{2} \mathrm{Mo}_{5} \mathrm{O}_{23}\right)\right] \times 4 \mathrm{H}_{2} \mathrm{O}\left(\mathrm{HL}=\mathrm{C}_{6} \mathrm{H}_{6} \mathrm{~N}_{2} \mathrm{O}\right)$ into nanostructures via a sonochemical method. Transmission electron microscopy (TEM) indicated that AgZnO/POMs nanocomposites were uniform with narrow particle size distribution and without agglomeration. X-ray powder diffraction (XRD) and X-ray photoelectron spectroscopy (XPS) analysis confirmed the nanostructure and composition of AgZnO/POMs nanocomposites. The ultraviolet-visible spectra (UV-vis) and photoluminescence spectra $(\mathrm{PL})$ confirmed excellent optical properties of the AgZnO/POMs nanocomposites. $94.0 \%$ of basic magenta (BM) in aqueous solution could be removed using the $\mathrm{AgZnO/POMs} \mathrm{nanocomposites} \mathrm{through}$ adsorption and photocatalysis. The kinetic analysis showed that both the adsorption and photocatalysis process conform to pseudo-second-order kinetics. In addition, the removal efficiency of AgZnO/POMs nanocomposites was found to be almost unchanged after 5 cycles of use. The bifunctional photocatalytic-adsorbent AgZnO/POMs nanocomposites with high stability and cycling performance have broad application prospects in the treatment of refractory organic dye wastewater containing triphenylmethane.

\section{Introduction}

With the development of industry, a large number of toxic and harmful organic wastewater has caused a series of environmental problems, which seriously threaten human health [1-4]. Basic magenta (BM) is a kind of refractory organic pollutant containing triphenylmethane. BM is widely used as a coloring, in industries such as textile and leather, and also as a colorant for the stain of collagen, tuberculosis and muscle $[5,6]$. It is urgently needed to be removed from the aqueous solution for the reason of that BM poses a great threat to water resources due to its poor biodegradability, toxicity and carcinogenicity. According to the literature, the removal method of BM in aqueous solution is mainly adsorption $[7,8]$. However, the application of BM dye adsorbents subject to the disadvantages of low adsorption capacity, slow kinetic speed and low recovery potential. It is still a challenge to explore a cleaner and more effective method to remove BM from aqueous solution.

Polyoxometalates (POMs), a promising adsorbent, has been applied in environmental protection because of their rich composition and structure, high thermal stability, adjustable acidity and reversible redox properties et al [9-13]. As adsorbent, POMs have been used to synthesize a variety of materials to remove different dyes from aqueous solutions [14-17]. Liu's research group has reported a case of $\mathrm{Fe}_{3} \mathrm{O}_{4} / \mathrm{POMs}$ nanomaterial with good adsorption performance for removal of cationic dyes, and a case of $\mathrm{Fe}_{3} \mathrm{O}_{4} / \mathrm{Ag} / \mathrm{POMs}$ nanomaterial with rapid removal of methylthionine chloride, indicating that more effective dye removal enhancement performance could be obtained by combining POMs and nanoparticles into a single entity through nanoengineering $[18,19]$. 
AgZnO hybrid nanoparticles have excellent photocatalytic activity and are widely used in the field of photocatalysis. The addition of Ag improves photocatalytic capacity of $\mathrm{AgZnO}$ and the charge utilization efficiency and photochemical stability of $\mathrm{ZnO}$ [20-24]. Photocatalytic activity of AgZnO nanoparticles has photocatalytic effect on dyes in aqueous solution $[25,26]$. In order to explore an effective and environmentally friendly method for removing BM dye in aqueous solution, in this paper, we combined AgZnO hybrid nanoparticles and POMs to obtain bifunctional photocatalytic-adsorbent AgZnO/POMs nanocomposites. The removal experiments of BM demonstrated that photocatalytic-adsorbent AgZnO/POMs nanocomposites possessed both adsorption and photocatalytic effects on BM in aqueous solution with emerging high removal efficiency. The good adsorption, photocatalytic activity and reusability of the nanocomposites indicated that the bifunctional photocatalytic-adsorbent AgZnO/POMs nanocomposites are beneficial to protecting the environment.

\section{Experiment Section \\ 2.1. Materials}

Silver acetate (Agac, 99\%), Zinc(II) acetylacetonate (Zn(acac) 2, 99.9\%), PEO-PPO-PEO, n-octyl ether (99\%), 1,2-hexadecanediol (90\%), Copper perchlorate $\left(\mathrm{Cu}\left(\mathrm{ClO}_{4}\right)_{2} \cdot 6 \mathrm{H}_{2} \mathrm{O}, 98 \%\right)$, Sodium molybdate dihydrate $\left(\mathrm{Na}_{2} \mathrm{MoO}_{4} \cdot 2 \mathrm{H}_{2} \mathrm{O}, 99 \%\right)$, Pyridinecarboxamide $\left(\mathrm{C}_{6} \mathrm{H}_{6} \mathrm{~N}_{2} \mathrm{O}, 98 \%\right)$, and $\mathrm{NaOH}(98 \%)$ were purchased from Aladdin company (Shanghai, China). None of the materials were further purified.

\subsection{Synthesis of photocatalytic-adsorbent AgZnO/POMs nanocomposites}

The AgZnO and polyoxometalates $\left[\mathrm{Cu}(\mathrm{L})_{2}\left(\mathrm{H}_{2} \mathrm{O}\right)_{2}\right] \mathrm{H}_{2}\left[\mathrm{Cu}(\mathrm{L})_{2} \mathrm{P}_{2} \mathrm{Mo}_{5} \mathrm{O}_{23}\right] \cdot 4 \mathrm{H}_{2} \mathrm{O}$ (Cu-POMs) samples were synthesized using the method reported in the literature [21, 19]. Firstly, AgZnO hybrid nanoparticles were synthesized, $10 \mathrm{~mL}$ of octyl ether, Zn(acac) $2(0.0989 \mathrm{~g})$, 1,2-hexadecanediol $(0.6468 \mathrm{~g})$, Agac $(0.0259 \mathrm{~g})$ and PEO-PPO-PEO $(0.7874 \mathrm{~g})$ were added to a three-necked flask stir the mixture. The mixture was heated to $125^{\circ} \mathrm{C}$, then quickly raised to $280^{\circ} \mathrm{C}$, the experiment was completed. When the temperature is cooled, the AgZnO hybrid nanoparticles were taken out and washed, obtaining pure AgZnO hybrid nanoparticles. Then, Cu-POMs was synthesized, copper perchlorate $(0.093 \mathrm{~g}), 2$-pyridinecarboxamide $(0.061 \mathrm{~g})$, and 15 $\mathrm{mL}$ of deionized water were added to a beaker, and stirred and mixed. When the temperature was cooled to room temperature, $\mathrm{Na}_{2} \mathrm{MoO}_{4} \cdot 2 \mathrm{H}_{2} \mathrm{O}(0.24 \mathrm{~g})$, and deionized water $(10 \mathrm{~mL})$ were added to the solution and mixed well, and keep $\mathrm{pH}$ was maintained at 3 . The blue precipitate $\mathrm{Cu}-\mathrm{POMs}$ was obtained by filtration. A mixture of reactants was obtained by adding $50 \mathrm{mg}$ POMs powders and $5 \mathrm{mg} \mathrm{AgZnO}$ hybrid nanoparticles into beaker containing $5 \mathrm{~mL}$ water and $5 \mathrm{~mL}$ ethanol, then ultrasound to obtain a uniform liquid. This process combines the AgZnO hybrid nanoparticles with $\mathrm{Cu}-\mathrm{POMs}$ to form nanostructures. Finally, the samples were dried to obtain a bifunctional AgZnO/POMs nanocomposite with both photocatalysis and adsorption effects.

\subsection{Analysis}


The structure and morphology of the photocatalytic adsorbent AgZnO/POMs nanocomposites were analyzed by XRD (X'Pert Pro, Bruker, Germany) and TEM (JEM-2100 JEOL Ltd., Japan) including HRTEM. The optical properties of photocatalytic adsorbent AgZnO/POMs nanocomposites were characterized by UV-vis (Hitachi U4100, Japan) and PL spectroscopy (Hitachi F7000, Japan). The FTIR spectra of nanocomposites were recorded using Avatar 360 FTIR spectrometer (Nicolet Company, USA). The XPS were performed on photoelectron spectrometer (Thermo Fisher Scientific ESCALAB 250XI, United States) Al Ka X-ray used as the excitation source.

\subsection{Dye removal experiment}

The removal activity was researched by analysing the removal efficiency of BM from aqueous solution. In the removal experimental study, a 36 W UV lamp (Philips, Netherlands, emitting mainly $365 \mathrm{~nm}$ ) and a $500 \mathrm{~W}$ Xenon lamp as light source. The dye was dissolved in water to prepare $15 \mathrm{mg} / \mathrm{L}$ BM aqueous solution (room temperature condition, $\mathrm{pH}=6.3$ ). The $5 \mathrm{mg}$ nanocomposites were added into $40 \mathrm{~mL}(15$ $\mathrm{mg} / \mathrm{L}) \mathrm{BM}$ solution for experiments. The solution was magnetically stirred at room temperature. At different time intervals, the about $5 \mathrm{~mL}$ solution was removed and centrifuged for $3 \mathrm{~min}$. The absorption peak intensity of BM at the maximum wavelength of $545 \mathrm{~nm}$ was analyzed by UV-Vis spectrophotometer.

\section{Results And Discussion}

\subsection{TEM analysis of photocatalytic adsorbent AgZnO/POMs nanocomposites}

The particle size distribution and morphology of photocatalytic-adsorbent AgZnO/POMs nanocomposites were analyzed by TEM and SEM. In Fig. 1a, the AgZnO/POMs nanocomposites are uniform particles size without agglomeration. By measuring the TEM micrographs of AgZnO/POMs nanocomposites, the histogram of particle size distribution was obtained. The average particle size of AgZnO/POMs nanocomposites was about $19.5 \mathrm{~nm}$, which was consistent with the Gaussian distribution. Figure $1 \mathrm{~b}$ is the HRTEM image of AgZnO/POMs nanocomposite. Apparently, the nanocomposites are distributed with highly regular lattices, which the spacing of $1.44 \AA$ corresponds to the Ag (220) plane, while the spacing of $2.47 \AA$ is $\mathrm{ZnO}(101)$ planes. A spacing of about $1 \mathrm{~nm}$ between the blue dotted line and the green dotted line may be distributed with POMs [27]. Element mapping (Fig. 1(c-k)) confirmed the distribution of $\mathrm{P}, \mathrm{O}, \mathrm{Ag}, \mathrm{Cu}, \mathrm{Mo}, \mathrm{N}, \mathrm{C}$ and $\mathrm{Zn}$ in the AgZnO/POMs nanocomposites, showed that AgZnO and POMs existed simultaneously in AgZnO/POMs nanocomposites. The results confirmed the formation of photocatalytic adsorbent AgZnO/POMs nanocomposites.

\subsection{XRD analysis of photocatalytic adsorbent AgZnO/POMs nanocomposites}

The structure of prepared photocatalytic adsorbent AgZnO/POMs nanocomposites was analyzed by XRD. In Fig. 2c, the diffraction peaks marked by the purple column diagrams of AgZnO hybrid 
nanoparticles at $38.2^{\circ}, 44.4^{\circ}, 64.6^{\circ}$ and $77.4^{\circ}$ correspond to the characteristic peaks of Ag (JCPDS No. 040783). The peaks marked by the blue column diagrams at $31.7^{\circ}, 34.5^{\circ}, 36.5^{\circ}, 47.6^{\circ}, 56.7^{\circ}, 62.8^{\circ}$ and $67.7^{\circ}$ correspond to $\mathrm{ZnO}$ (JCPDS No. 36-1451) characteristic diffraction peak. The peaks at $8.7^{\circ}-30.7^{\circ}$ in Fig. $2 \mathrm{~b}$ are the diffraction peaks of POMs [19]. In the diffraction pattern of photocatalytic adsorbent AgZnO/POMs nanocomposites (Fig. 2a), the diffraction peaks of POMs (Fig. 2b) and AgZnO hybrid nanoparticles (Fig. 2c) reappear simultaneously. The results confirmed the formation of AgZnO/POMs nanocomposites.

\subsection{FTIR analysis of photocatalytic adsorbent AgZnO/POMs nanocomposites}

The FTIR spectra of AgZnO/POMs nanocomposites, POMs, and AgZnO hybrid nanoparticles had been depicted in Fig. 3 (a-c). As shown in Fig. 3a, the vibration peak at $3370 \mathrm{~cm}^{-1}$ is caused by the $\mathrm{H}_{2} \mathrm{O}$ hydrogen bond. The vibration peak appearing in the interval of $1680-1133 \mathrm{~cm}^{-1}$ is attributed to the ligand 2-pyridinecarboxamide. The stretching vibration of the P-O bond appears in the range of 1120 $1008 \mathrm{~cm}^{-1}[28,29]$. The vibrational peaks at $905 \mathrm{~cm}^{-1}$ and $662 \mathrm{~cm}^{-1}$ are attributed to the $v$ (Mo$\left.\mathrm{O}_{\text {bridging }}\right)$ bond and the $v\left(\mathrm{Mo}-\mathrm{O}_{\text {terminal }}\right)$ bond, respectively [29]. The characteristic absorption peaks in POMs appear in the map of photocatalytic-adsorbent AgZnO/POMs nanocomposites. In Fig. 3c, the strong absorption at $512 \mathrm{~cm}^{-1}$ clearly reflects the vibration of the $\mathrm{Zn}-\mathrm{O}$ bond, and the corresponding peak also appears in Figuer 3b [30]. The above characteristic absorption peaks also exist in the FTIR spectra of photocatalytic adsorbent AgZnO/POMS nanocomposites (Fig. 3b), confirmed that the nanocomposites had been synthesized.

\subsection{XPS analysis of photocatalytic adsorbent AgZnO/POMs nanocomposites}

In Fig. 4, the XPS spectrum was calibrated using C1s (284.8 eV). The peaks of C, O, N, P, Zn, Mo, Cu and Ag can be observed from the full spectrum of XPS (Fig. 4a). In Fig. 4b, the AgZnO/POMs nanocomposites shows two peaks of binding energy at approximately $1022 \mathrm{eV}$ and $1045 \mathrm{eV}$, corresponding to the main regions of $Z n 2 p_{3 / 2}$ and $Z n 2 p_{1 / 2}$ [31]. The first peak is attributed to the $Z^{2+}$ ion in the anoxic zinc oxide [32]. The peaks at $367.2 \mathrm{eV}$ and $373.2 \mathrm{eV}$ (Fig. 4c) correspond to $\mathrm{Ag} 3 \mathrm{~d}_{5 / 2}$ and $3 \mathrm{~d}_{3 / 2}$ states of metal Ag. Compared with bulk silver (about $368.2 \mathrm{eV}$ and $374.2 \mathrm{eV}$, respectively), the peaks of the Ag $3 \mathrm{~d}$ state is significantly transferred to the lower value of $\mathrm{AgZnO}$ hybrid nanoparticles, which is attributed to contact between $\mathrm{Ag}$ and $\mathrm{ZnO}$ [33]. Figure 4d shows peaks at $934.9 \mathrm{eV}$ and $932.4 \mathrm{eV}$, which are in the energy region of $\mathrm{Cu} 2 \mathrm{p}_{3 / 2}$ and $\mathrm{Cu} 2 \mathrm{p}_{1 / 2}$ attributed to $\mathrm{Cu}^{2+}$, indicating that $\mathrm{Cu}$ is mainly present in the form of $\mathrm{Cu}^{2+}$ $[34,35]$. Figure 4 e shows peaks at 133.2 and $134.1 \mathrm{eV}$, corresponding to the P-O peaks of $P 2 p_{3 / 2}$ and $P$ $2 p_{1 / 2}$, respectively [36]. In Fig. $4 f$, shows peaks at 235.8 and $232.3 \mathrm{eV}$, corresponding to the main regions of $\mathrm{Mo} 3 \mathrm{~d}_{3 / 2}$ and $\mathrm{Mo} 3 \mathrm{~d}_{5 / 2}$ respectively, indicating that the valence of Mo is mainly $\mathrm{Mo}^{6+}$ [37]. The analysis shows that AgZnO/POMs nanocomposites contain AgZnO and POMs. 


\subsection{UV-vis analysis of photocatalytic adsorbent AgZnO/POMs nanocomposites}

UV-vis absorption spectrum of photocatalytic-adsorbent AgZnO/POMs nanocomposites in aqueous solution in Fig. 5. The AgZnO/POMs nanocomposites have four absorption bands at $209 \mathrm{~nm}, 260 \mathrm{~nm}$, $365 \mathrm{~nm}$ and $380-420 \mathrm{~nm}$, respectively. The absorption band at $365 \mathrm{~nm}$ is the characteristic absorption band of $\mathrm{ZnO}$ [21]. The absorption at 380-420 nm reveals the hybridization of $\mathrm{ZnO}$ with $\mathrm{Ag}$ and the interfacial electron interaction between $\mathrm{Ag}$ and ZnO [38]. The absorption bands at $209 \mathrm{~nm}$ and $260 \mathrm{~nm}$ are attributed to POMs because of electron transfer of $\mathrm{O}_{\text {terminal }} \rightarrow$ Mo and $\mathrm{O}_{\text {bridging }} \rightarrow$ Mo in POMs [19]. The results show that the AgZnO/POMs nanocomposites have excellent optical properties.

\subsection{PL analysis of photocatalytic adsorbent AgZnO/POMs nanocomposites}

The solid fluorescence emission spectra of photocatalytic-adsorbent AgZnO/POMs nanocomposites were detected under the excitation wavelength of $241 \mathrm{~nm}$ (Fig. 6a) and $380 \mathrm{~nm}$ (Fig. 6b), respectively. As shown in Fig. 6a, AgZnO/POMs nanocomposites have an emission peak at $393 \mathrm{~nm}$, corresponding to the solid-state fluorescence emission peaks at $393 \mathrm{~nm}$ of POMs [39]. Figure 6b AgZnO/POMs nanocomposites shows three emission peaks at $465 \mathrm{~nm}, 489 \mathrm{~nm}$ and $596 \mathrm{~nm}$ corresponding to the emission peaks of AgZnO hybrid nanoparticles, respectively. The blue light emission peaks at $465 \mathrm{~nm}$ and $489 \mathrm{~nm}$ are usually caused by photo-generated holes of $\mathrm{ZnO}$ and the oxygen vacancies occupied by the nanocomposites [40]. The emission at about $596 \mathrm{~nm}$ is generally thought to be caused by the recombination of electrons and valence band holes in the deep defect layer of ZnO [41]. The results show that the AgZnO/POMs nanocomposites have excellent optical properties.

\section{Removal Of Bm}

The adsorption and photocatalytic activities of AgZnO/POMs nanocomposites were studied by removing BM from aqueous solution. Figure $7 \mathrm{a}$ is the UV-vis absorption spectra of BM solution containing the AgZnO/POMs nanocomposites at different intervals. Figure 7b shows a comparative study for removing $\mathrm{BM}$ in the presence of (1) POMs, (2) AgZnO and (3) AgZnO/POMs nanocomposites, in which, the ordinate is $\mathrm{C} / \mathrm{C}_{0}$, where $\mathrm{C}$ is the corresponding concentration of $\mathrm{BM}$ at different time intervals, and $\mathrm{C}_{0}$ is the original concentration of BM. It can be observed in combination with Figure 7(a) and (b), the absorption peak strength of BM gradually decreases in 0-30 min, remaining unchanged in 30-50 min for reaching adsorption equilibrium under stirring in the dark, then after $50 \mathrm{~min}$, decreases with the increase of UV-light irradiation, indicating the adsorption and photocatalysis activities of AgZnO /POMs nanocomposites. In Figure 7b, POMS only showed adsorption, while the adsorption and photocatalysis of AgZnO hybrid nanoparticles were relatively weak, when the two are combined, AgZnO/POMs nanocomposite has enhanced adsorption effect relative to AgZnO hybrid nanoparticles, and shows photocatalytic effect relative to POMS, and finally achieves $94 \%$ removal rate of BM in aqueous solution. Figure $7 \mathrm{c}$ shows a 
comparative histogram of the removal of $\mathrm{BM}$ by POMs, AgZnO, and AgZnO/POMs nanocomposites under UV-light and Vis irradiation, respectively. No matter under UV or visible light irradiation, the photocatalytic-adsorbent AgZnO/POMs qualifies higher removal efficiency than the adsorbent POMs and photocatalyst AgZnO. The removal rate of AgZnO/POMs for removing BM is $94 \%$, which is much higher than that of POMs (54\%) and AgZnO (73\%) under UV-light irradiation.

The $\mathrm{N}_{2}$ adsorption-desorption isotherms of AgZnO nanoparticles and photocatalytic-adsorbent AgZnO/POMS nanocomposites were determined using the automatic physical/chemical adsorption apparatus. In Figure 8, both samples showed typical type IV isotherms, indicating the presence of mesoporous structures [42]. According to the analysis results of relative position and height of hysteresis loops (Figure 8), the specific surface area (BET) of AgZnO nanoparticles (Figure 8a) is $28.682 \mathrm{~m}^{2} / \mathrm{g}$, The BET of AgZnO/POMs nanocomposite (Figure $8 b$ ) is $33.535 \mathrm{~m}^{2} / \mathrm{g}$. The results indicate that the AgZnO/POMS nanocomposites obtained by the combination of the two have higher specific surface area, which corresponds to the enhanced adsorption performance of the composite under dark conditions.

The pseudo-first-order and pseudo-second-order kinetic models were used to fit the experimental data of AgZnO/POMs nanocomposites.

$$
\begin{gathered}
\ln \left(q_{e}-q_{t}\right)=\ln q_{e}-k_{1} t \\
\frac{t}{q_{t}}=\frac{1}{k_{2}\left(q_{e}\right)^{2}}+\frac{t}{q_{e}}
\end{gathered}
$$

In the (1) and (2), $q_{0}$ is adsorption amount at $t=0, q_{\mathrm{e}}$ is equilibrium adsorption amount, $q_{\mathrm{t}}$ is adsorption amount at time $t, k_{1}$ and $k_{2}$ are the pseudo-first-order and pseudo-second-order kinetic rate constants, respectively.

\begin{tabular}{|c|c|c|}
\hline & Pseudo-first-order & Pseudo-second-order \\
\hline & $R^{2}$ & $R^{2}$ \\
\hline Dark & 0.3471 & 0.9997 \\
\hline UV light & 0.9380 & 0.9736 \\
\hline
\end{tabular}

Table 1. Kinetic correlation coefficients $\left(R^{2}\right)$ fitting parameters.

The kinetic plots of removing BM by AgZnO/POMs nanocomposites are shown in Figure 9 and the results are shown in Table 1. The $R^{2}$ of pseudo-second-order model were 0.9997 and 0.9736 under dark and UVlight respectively which were higher than that of pseudo-first-order model, 0.3471 and 0.9380 under dark and UV-light respectively, indicating that both the adsorption process and the photocatalysis process of removing BM by AgZnO/POMs nanocomposites followed the pseudo-second-order kinetics. The results 
demonstrate that the removal rate of $\mathrm{AgZnO/POMs} \mathrm{nanocomposites} \mathrm{is} \mathrm{mainly} \mathrm{due} \mathrm{to} \mathrm{the} \mathrm{chemical}$ adsorption and electron transfer ability of the composites $[27,43]$.

When AgZnO/POMs nanocomposites were excited by UV light, the photogenerated $e^{-}$and hole $\left(h^{+}\right)$will be produced by $\mathrm{ZnO}$. Ag acts as an electron acceptor, by which chemisorbed molecular oxygen reacts with photogenerated $e^{-}$to form superoxide radicals $\left({ }^{\circ} \mathrm{O}_{2}^{-}\right)$, facilitating the trapping of photogenerated $e^{-}$, and thus the separation efficiency of the photogenerated $e^{-}$and $h^{+}$is improved. The $h^{+}$in the valence band of $\mathrm{ZnO}$ react with hydroxyl groups to form hydroxyl radicals $\left({ }^{\circ} \mathrm{OH}\right)$, the ${ }^{\circ} \mathrm{OH}$ is a strong oxidant for removing the organic chemicals. The $h^{+},{ }^{\circ} \mathrm{OH}$ and ${ }^{\circ} \mathrm{O}_{2}{ }^{-}$produced in the process of photocatalysis are crucial substances for BM removal, in addition to the adsorption between the adsorbent and the dye molecules [19, 27, 44]. As a result, the removal efficiency of AgZnO/POMS nanocomposites was greatly improved by the combination of $\mathrm{AgZnO}$ and POMs into a whole through nanoengineering. The photocatalytic-adsorbent AgZnO/POMs nanocomposites are expected to be a new type of dye removers which can remove aromatic organic dyes from water pollution more efficiently, especially for BM, which is difficult to remove.

To investigate the reproducibility of the nanocomposites for removing BM, we collected and washed the AgZnO/POMs nanocomposites. The collected nanocomposites were used to remove BM via five repeated experiments under the same reaction conditions. As shown in Figure 11a, the removal rate of BM in AgZnO/POMs nanocomposites decreased by only $7.0 \%$ (from $94.0 \%$ to $87.0 \%$ ) after five cycles, the slight reduction might correspond to the loss of AgZnO/POMs nanocomposites during washing. Figure $11 \mathrm{~b}$ shows that the FTIR spectrum of the AgZnO/POMs nanocomposites before and after BM removal are similar. It could be proved that the nanocomposites have the well stability and light corrosion of resistance.

\section{Conclusions}

In conclusion, the photocatalytic-adsorbent AgZnO/POMs nanocomposites were synthesized by combining AgZnO hybrid nanoparticles and POMs. The TEM and HRTEM showed that AgZnO/POMs nanocomposites were uniform with narrow particle size distribution and without agglomeration. The bifunctional photocatalytic-adsorbent AgZnO/POMs nanocomposites could effectively remove refractory BM from aqueous solution with removal efficiency of $94 \%$ by adsorption and photocatalysis. The adsorption process and the photo-degradation process of AgZnO/POMs nanocomposites for removing $\mathrm{BM}$ followed the pseudo-second-order kinetics. After five cycles, the removal efficiency of nanocomposites for BM remained the same, and the FTIR spectrum of the AgZnO/POMs nanocomposites after the removal of BM were similar to the fresh samples, demonstrating that the nanocomposites have the well stability and light corrosion of resistance. The bifunctional photocatalyticadsorbent AgZnO/POMs nanocomposites have potential applications in the treatment of refractory organic dye wastewater containing triphenylmethane. 


\section{Declarations}

\section{Conflicts of Interest}

The authors declare no conflict of interest.

\section{Acknowledgment}

The authors gratefully acknowledge Key Lab of Polyoxometalate Chemistry of Henan Province and School of Chemistry and Chemical Engineering, Henan University lab,for the Instrument sharing platform.

\section{Funing}

This work was supported in part by the National Natural Science Foundation of China (No. 51172064).

\section{Authors' contributions}

Heyun Tian, Jie Luo and Chenguang Ma designed the concept and conducted the experiments. Heyun Tian and Jie Luo, wrote the main manuscript. Heyun Tian, Chenguang Ma, Ke Zhang, Yiyi Qi and Shixia Zhan conducted data processing and analysis. Heyun Tian, Jie Luo, Hongling Liu and Mingxue Li modified the paper.

\section{References}

1. Chu W (2001) Dye removal from textile dye wastewater using recycled alum sludge. Wat Res 35:3147-3152. https://doi.org/10.1016/S0043-1354(01)00015-X

2. Yaseen DA, M. Scholz, Textile dye wastewater characteristics and constituents of synthetic effluents: a critical review, Int J Environ Sci Te 16 (2019) 1193-1226. https://doi.org/10.1007/s13762-0182130-z

3. Abdel-Ghani NT, Hefny M, El-Chaghaby GAF (2007) Removal of lead from aqueous solution using low cost abundantly available adsorbents. Int J Environ Sci Te 4:67-73.

https://doi.org/10.1007/BF03325963

4. Liu N, Huang WY, Zhang XD, Tang L, Wang L, Wang YX, Wu MH (2018) Ultrathin graphene oxide encapsulated in uniform MIL-88A(Fe) for enhanced visible light-driven photodegradation of RhB. Appl Catal B Environ 221:119-128. https://doi.org/10.1016/j.apcatb.2017.09.020

5. Bayramoglu G, Altintas B, Arica MY (2009) Adsorption kinetics and thermodynamic parameters of cationic dyes from aqueous solutions by using a new strong cation-exchange resin. Chem Eng $\mathrm{J}$ 152:339-346. https://doi.org/10.1016/j.cej.2009.04.051

6. Tokalıoğlu Ş, Yavuz E, Aslantaş A, Şahan H, Taşkın F, Patat Ş (2015) Spectrophotometric determination of basic fuchsin from various water samples after vortex assisted solid phase extraction using reduced graphene oxide as an adsorbent. Spectrochim Acta A 149:378-384. https://doi.org/10.1016/j.saa.2015.04.089 
7. Mohammadine EH, Removal of basic fuchsin dye from water using mussel shell biomass waste as an adsorbent: Equilibrium, kinetics, and thermodynamics, J. Taibah. Univ. Sci. 10 (2016) 664-674. https://doi.org/10.1016/j.jtusci.2015.08.007

8. Kalita S, Pathak M, Devi G, Sarma HP, Bhattacharyya KG, Sarma A, Devi A (2017) Utilization of Euryale ferox Salisbury seed shell for removal of basic fuchsin dye from water: equilibrium and kinetics investigation. RSC Adv 7:27248-27259. https://doi.org/10.1039/c7ra03014b

9. Costa-Coquelard C, Schaming D, Lampre I, Ruhlmann L (2008) Photocatalytic reduction of $\mathrm{Ag}_{2} \mathrm{SO}_{4}$ by the Dawson anion $\mathrm{a}-\left[\mathrm{P}_{2} \mathrm{~W}_{18} \mathrm{O}_{62}\right]^{6-}$ and tetracobalt sandwich complexes. Appl Catal $\mathrm{B}$ Environ 84:835-842. https://doi.org/10.1016/j.apcatb.2008.06.018

10. Heravi MM, Sadjadi S (2016) Recent advances in applications of POMs and their hybrids in catalysis. Current Organic Chemisty 20:1404-1444. https://doi.org/10.2174/1385272820666160216225330

11. Mizuno N, Misono M (1998) Heterogeneous catalysis. Chem Rev 98:199-218. https://doi.org/10.1021/cr960401q

12. Bassil BS, Ibrahim M, Al-Oweini R, Asano M, Wang Z, Johan VT, Naresh SD, Kwang-Yong C, Biboum RN, Keita B, Nadjo L, Kortz U (2011) A planar $\left\{\mathrm{Mn}_{19}(\mathrm{OH})_{12}\right\}^{26+}$ unit incorporated in a 60-tungsto-6silicate polyanion. Angew Chem Int Ed 50:5961-5964. https://doi.org/10.1002/anie.201007617

13. Lydon C, Busche C, Miras HN, Delf A, Long DL, Yellowlees L, Cronin L (2012) Nanoscale growth of molecular oxides: assembly of a $\left\{\mathrm{V}_{6}\right\}$ double cubane between two lacunary $\left\{\mathrm{P}_{2} \mathrm{~W}_{15}\right\}$ polyoxometalates. Angew Chem Int Ed 51:2115-2118. https://doi.org/10.1002/ange.201105829

14. Zhang S, Wang X, Zhang HX, Zhao ZH, Wang XL (2018) Solvent-tuned polyoxometalate-based supramolecular hybrids constructed from different metal-organic motifs: Various structures and adsorption properties for dyes. Chinese Chem Lett 29:309-312. https://doi.org/10.1016/j.cclet.2017.08.044

15. Zeng L, Xiao L, Long Y, Shi X (2018) Trichloroacetic acid-modulated synthesis of polyoxometalate@UiO-66 for selective adsorption of cationic dyes. J Colloid Interf Sci 516:274-283. https://doi.org/10.1016/j.jcis.2018.01.070

16. Yi FY, Zhu W, Dang S, Li JP, Wu D, Li YH, Sun ZM (2015) Polyoxometalates-based heterometallic organic-inorganic hybrid materials for rapid adsorption and selective separation of methylene blue from aqueous solutions. Chem Commun 51:3336-3339. https://doi.org/10.1039/C4CC09569C

17. Liu X, Gong W, Luo J, Zou C, Yang Y, Yang S (2016) Selective adsorption of cationic dyes from aqueous solution by polyoxometalate-based metal-organic framework composite. Appl Surf Sci 362:517-524. https://doi.org/10.1016/j.apsusc.2015.11.151

18. Fang N, Ji YM, Li CY, Wu YY, Ma CG, Liu HL, Li MX, Synthesis and adsorption properties of $\left[\mathrm{Cu}(\mathrm{L})_{2}\left(\mathrm{H}_{2} \mathrm{O}\right)\right] \mathrm{H}_{2}\left[\mathrm{Cu}(\mathrm{L})_{2}\left(\mathrm{P}_{2} \mathrm{Mo}_{5} \mathrm{O}_{23}\right)\right] \cdot 4 \mathrm{H}_{2} \mathrm{O} / \mathrm{Fe}_{3} \mathrm{O}_{4}$ nanocomposites, RSC Adv. 7 (2017) 25325-25333. https://doi.org/10.1039/c7ra02133j 
19. Zhan SX, Li CY, Tian HY, Ma CG, Liu HL, Luo J, Li MX (2019) Synthesis, characterization and dye removal behavior of core-shell-shell $\mathrm{Fe}_{3} \mathrm{O}_{4} / \mathrm{Ag} /$ Polyoxometalates ternary nanocomposites.

Nanomaterials 9:1255. https://doi.org/10.3390/nano9091255

20. Yang F, Li Y, Hou H, Hu F, Zhang JX, Wang Y (2016) Facile synthesis of ZnO/Ag nanocomposites with enhanced photocatalytic properties under visible light. Mater Lett 180:97-100. https://doi.org/10.1016/j.matlet.2016.05.117

21. Wang XH, Liu HL, Zhang WX, Cheng WZ, Liu X, Li XM, Wu JH (2014) Synthesis and characterization of polymer-coated AgZnO nanoparticles with enhanced photocatalytic activity. RSC Adv 4:4401144017. https://doi.org/10.1039/c4ra09382h

22. Georgekutty R, Seery MK, Pillai SC (2008) A highly efficient Ag-ZnO photocatalyst: synthesis, properties and mechanism. J Phys Chem C 112:13563-13570. https://doi.org/10.1021/jp802729a

23. Liu Y, Wei S, Gao W (2015) Ag/ZnO heterostructures and their photocatalytic activity under visible light: effect of reducing medium. J Hazard Mater 287:59-68.

https://doi.org/10.1016/j.jhazmat.2014.12.045

24. Yousefi HR, Hashemi B (2019) Photocatalytic properties of Ag@Ag-doped ZnO core-shell nanocomposite. J Photoch Photobio A 375:71-76.

https://doi.org/10.1016/j.jphotochem.2019.02.008

25. Liu HR, Shao GX, Zhao JF, Zhang ZX, Zhang Y, Liang J, Xu BS (2012) Worm-like Ag/ZnO core-shell heterostructural composites: fabrication, characterization and photocatalysis. J Phys Chem C 116:16182-16190. https://doi.org/10.1021/jp2115143

26. Xie W, Li Y, Sun W, Huang J, Xie H, Zhao X (2010) Surface modification of ZnO with Ag improves its photocatalytic efficiency and photostability. J Photoch Photobio A 216:149-155.

https://doi.org/10.1016/j.jphotochem.2010.06.032

27. Li J, Zhao H, Ma CG, Han QX, Li MX, Liu HL (2019) Preparation of $\mathrm{Fe}_{3} \mathrm{O}_{4} @$ @polyoxometalates nanocomposites and their efficient adsorption of cationic dyes from aqueous solution.

Nanomaterials 9:649. https://doi.org/10.3390/nano9040649

28. D’Cruz B, Samuel J, George L (2014) Characterization, non-isothermal decomposition kinetics and photocatalytic water splitting of green chemically synthesized polyoxoanions of molybdenum containing phosphorus as hetero atom. Thermochim Acta 596:29-36.

https://doi.org/10.1016/j.tca.2014.09.010

29. Li ZL, Wang Y, Zhang LC, Wang JP, You WS, Zhu ZM (2014) Three molybdophosphates based on Strandberg-type anions and $\mathrm{Zn}(\mathrm{II})-\mathrm{H}_{2}$ biim/ $\mathrm{H}_{2} \mathrm{O}$ subunits: syntheses, structures and catalytic properties. Dalton T 43:5840-5846. https://doi.org/10.1039/c3dt53023j

30. Liu H, Wu J, Min JH, Zhang X, Kim YK (2013) Tunable synthesis and multifunctionalities of $\mathrm{Fe}_{3} \mathrm{O}_{4}$ ZnO hybrid core-shell nanocrystals. Mater Res Bull 48:551-558.

https://doi.org/10.1016/j.materresbull.2012.11.051

31. Lupan O, Emelchenko GA, Ursaki VV, Chai G, Redkin AN, Gruzintsev AN, Heinrich H (2010) Synthesis and characterization of ZnO nanowires for nanosensor applications. Mater Res Bull 45:1026-1032. 
https://doi.org/10.1016/j.materresbull.2010.03.027

32. Morozov IG, Belousova OV, Ortega D, Mafina MK, Kuznetcov MV (2015) Structural, optical, XPS and magnetic properties of Zn particles capped by ZnO nanoparticles. J Alloy Compd 633:237-245. https://doi.org/10.1016/j.jallcom.2015.01.285

33. Moulder JF, Stickle WF, Sobol PE, Bomben KD, Handbook of X-ray photoelectron spectroscopy, edited by J. Chastain (Perkin-Elmer, Eden Prairie, MN, 1992), 118

34. Biesinger MC, Lau LW, Gerson AR, Smart RSC (2010) Resolving surface chemical states in XPS analysis of first row transition metals, oxides and hydroxides. Appl Surf Sci 257:887-898. https://doi.org/10.1016/j.apsusc.2010.07.086

35. Al-Agel FA, Al-Arfaj E, Al-Ghamdi AA, Stein BD, Losovyj Y, Bronstein LM, Mahmoud WE (2015) Structure and magnetic properties of diluted magnetic metal oxides based on Cu-doped $\mathrm{CeO}_{2}$ nanopowders. Ceram Int 41:1115-1119. https://doi.org/10.1016/j.ceramint.2014.09.037

36. Liu T, Ali S, Lian Z, Si C, Su DS, Li B (2018) Phosphorus-doped onion-like carbon for $\mathrm{CO}_{2}$ electrochemical reduction: the decisive role of the bonding configuration of phosphorus. J Mater Chem A 6:19998-20004. https://doi.org/10.1039/c8ta06649c

37. Xiao D, Hou Y, Wang E, Wang S, Li Y, De G, Hu C (2003) Hydrothermal synthesis and crystal structure of a novel polyoxomolybdate with the hydroxylated $\mathrm{N}$-heterocycle ligand: $\mathrm{Mo}_{2} \mathrm{O}_{5}$ (ophen) ${ }_{2}$ (Hophen = 2-hydroxy-1,10-phenanthroline). J Mol Struct 659:13-21. https://doi.org/10.1016/S00222860(03)00363-6

38. Elemike EE, Onwudiwe DC, Wei L, Lou CG, Zhao WZ, Synthesis of nanostructured ZnO, AgZnO and the composites with reduced graphene oxide ( $\mathrm{rGO}-\mathrm{AgZnO})$ using leaf extract of stigmaphyllon ovatum, J Environ Chem Eng (2019) 103190. https://doi.org/10.1016/j.jece.2019.103190

39. Shi H, Yu Y, Zhang Y, Feng X, Zhao X, Tan HQ, Khan SU, Li YG, Wang EB (2018) Polyoxometalate/ $\mathrm{TiO}_{2} / \mathrm{Ag}$ composite nanofibers with enhanced photocatalytic performance under visible light. Appl Catal B-Environ 221:280-289. https://doi.org/10.1016/j.apcatb.2017.09.027

40. Taunk PB, Das R, Bisen DP, Tamrakar RK, Radiat J (2015) Structural characterization and photoluminescence properties of zinc oxide nanoparticles synthesized by chemical route method. Res Appl Sci 8:433-438. https://doi.org/10.1016/j.jrras.2015.03.006

41. Tong YH, Liu YC, Lu SX, Dong L, Chen SJ, Xiao ZY (2004) The optical properties of ZnO nanoparticles capped with polyvinyl butyral. J Sol-Gel Sci Technol 30:157-161. https://doi.org/10.1023/B:JSST.0000039500.48283.5a

42. Khudhair EM, Ammar SH, Khadim HJ (2021) Phosphotungstic acid immobilized onto ZnO coated zerovalent iron (Fe@ZnO/PW) core/shell magnetic nanocomposite for enhanced photocatalytic bacterial inactivation under visible light. J Photoch Photobio A Chemistry 404:112907. https://doi.org/10.1016/j.jphotochem.2020.112907

43. He JC, Li J, Du W, Han QX, Wang Z, Li MX (2018) A mesoporous metal-organic framework: Potential advances in selective dye adsorption. J Alloy Compd 750:360-367. https://doi.org/10.1016/j.jallcom.2018.03.393 
44. Liu J, Li J, Wei F, Zhao X, Su Y, Han X (2019) Ag-ZnO sub-micron rod arrays for high efficiency photocatalytic degradation of congo red and disinfection. ACS Sustainable Chem Eng 7:1125811266. https://doi.org/10.1021/acssuschemeng.9b00610

\section{Figures}
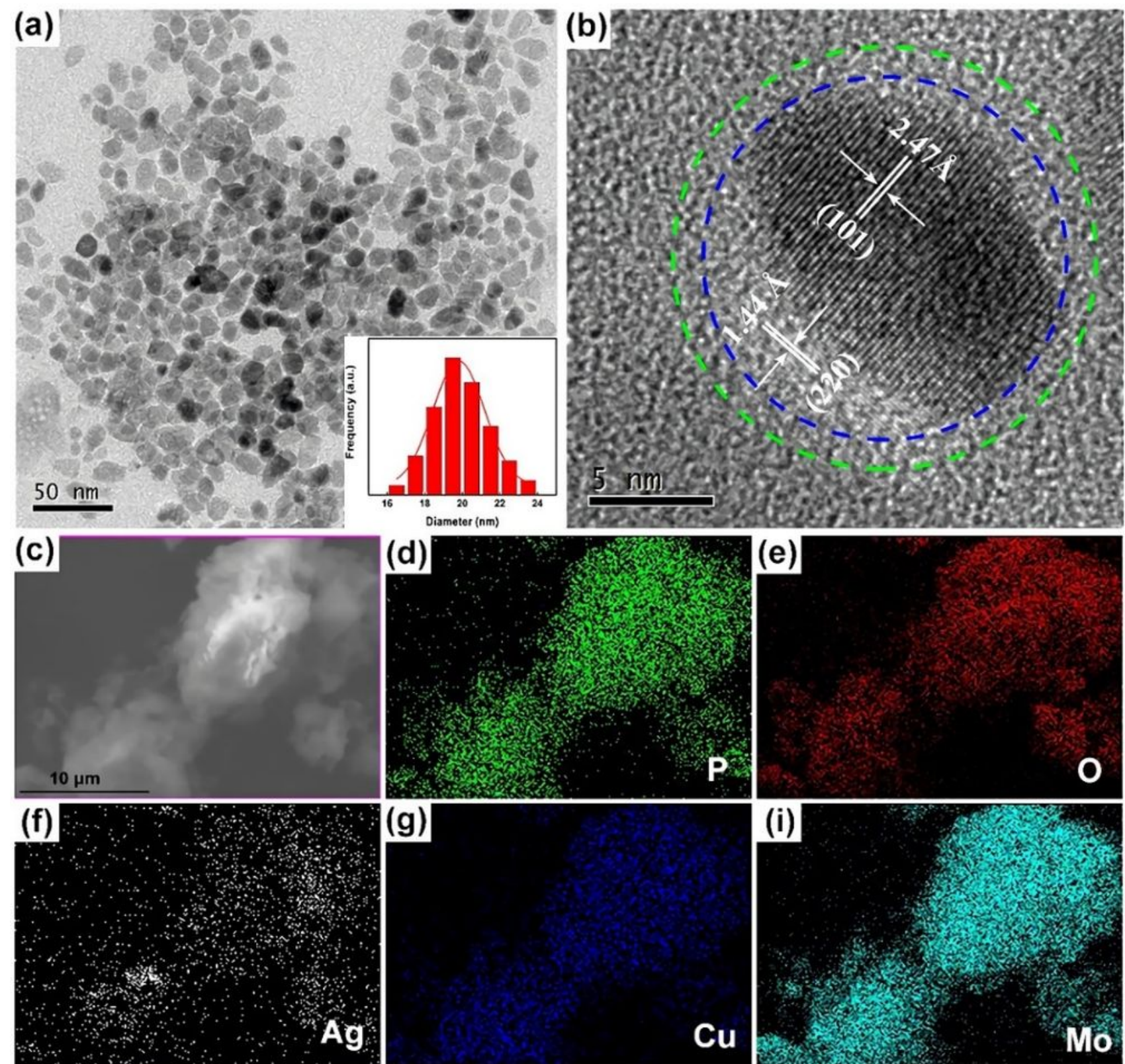

(e)

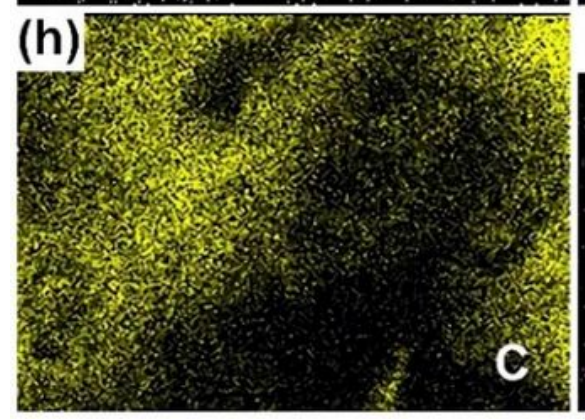

(j)

$\mathrm{Cu}$
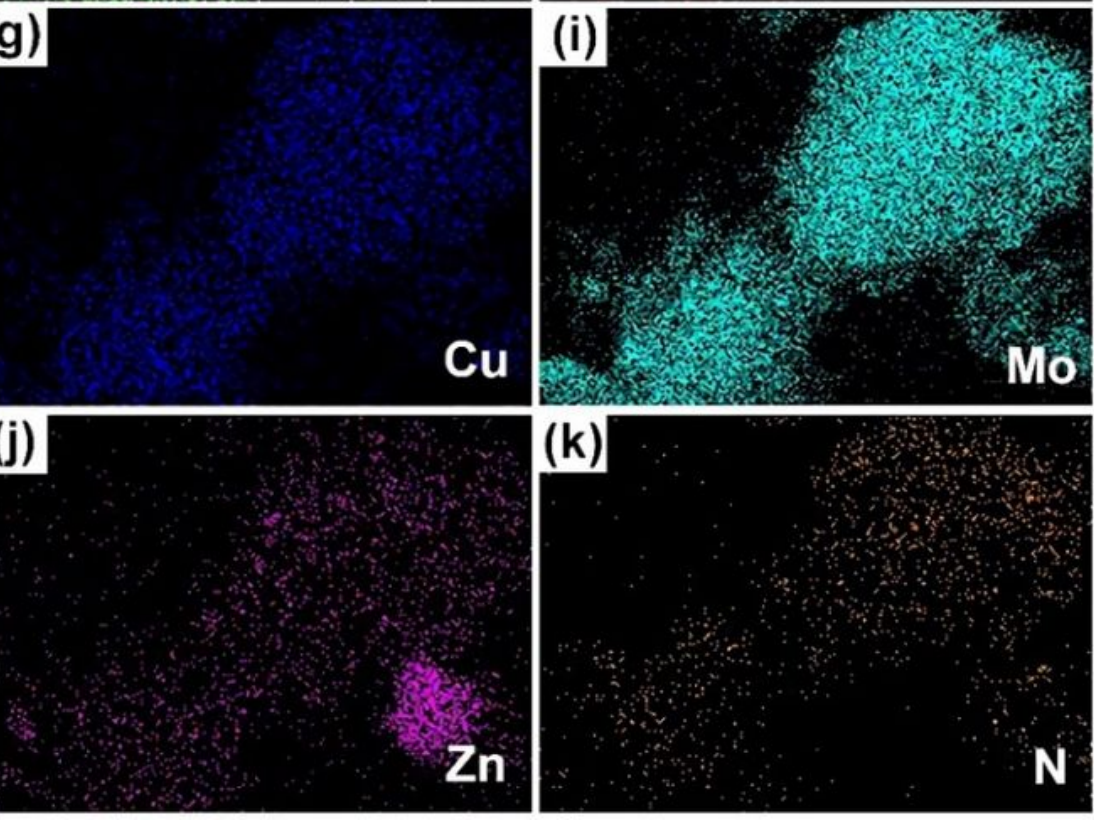

(k)

Figure 1 
(a) TEM micrographs and illustration shows particle size histogram of AgZnO/POMs nanocomposites,

(b) HRTEM of an individual AgZnO/POMs nanocomposite, (c) STEM micrographs and (d-k) corresponding elemental mappings of AgZnO/POMs nanocomposites.

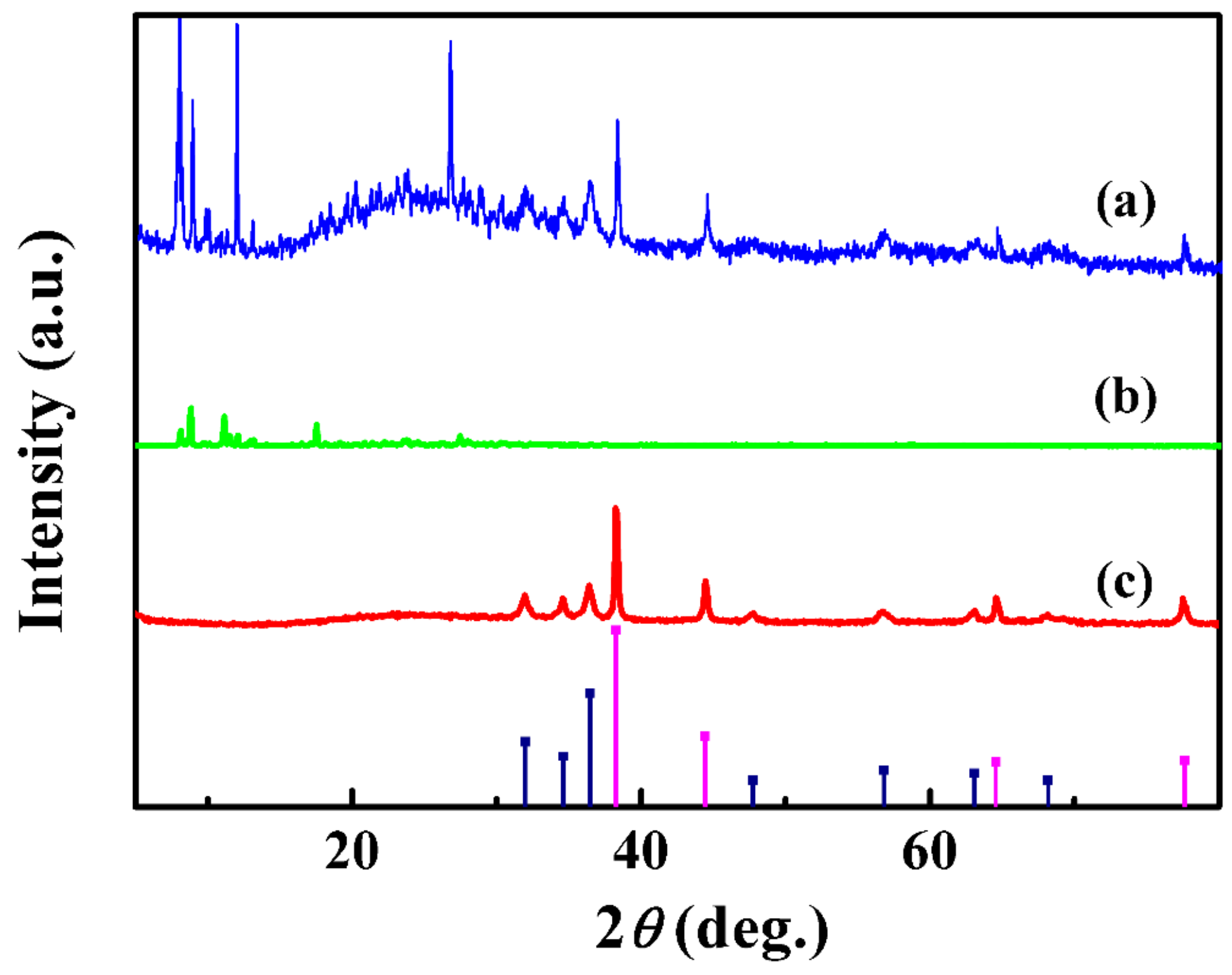

Figure 2

XRD patterns of (a) AgZnO/POMs nanocomposites, (b) POMs, (c) AgZnO hybrid nanoparticles (The purple and blue column charts are the column diagrams of $\mathrm{Ag}$ and $\mathrm{ZnO}$ labeled cards, respectively). 


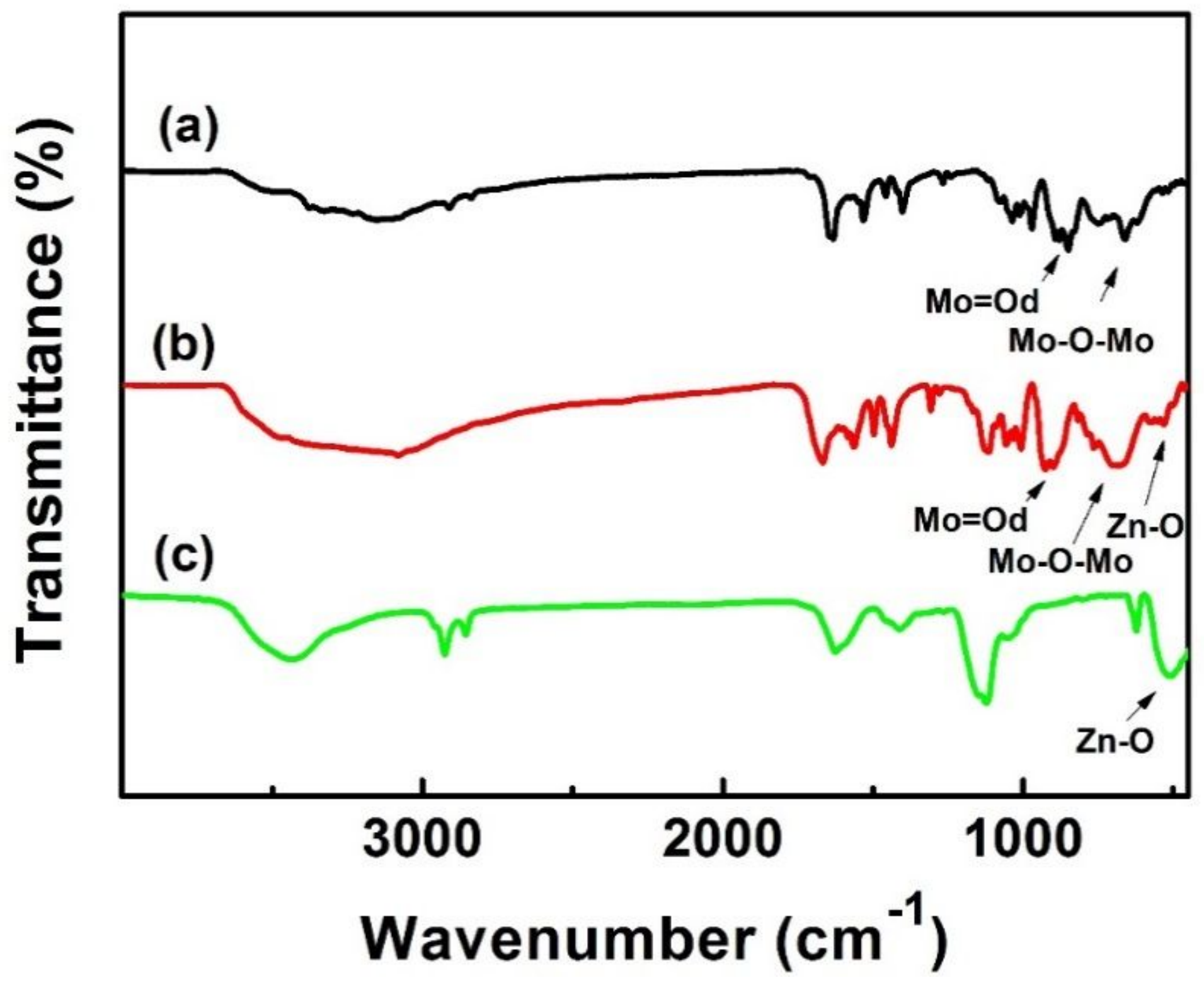

Figure 3

FTIR spectra of (a) POMs, (b) AgZnO/POMs nanocomposites and (c) AgZnO hybrid nanoparticles. 

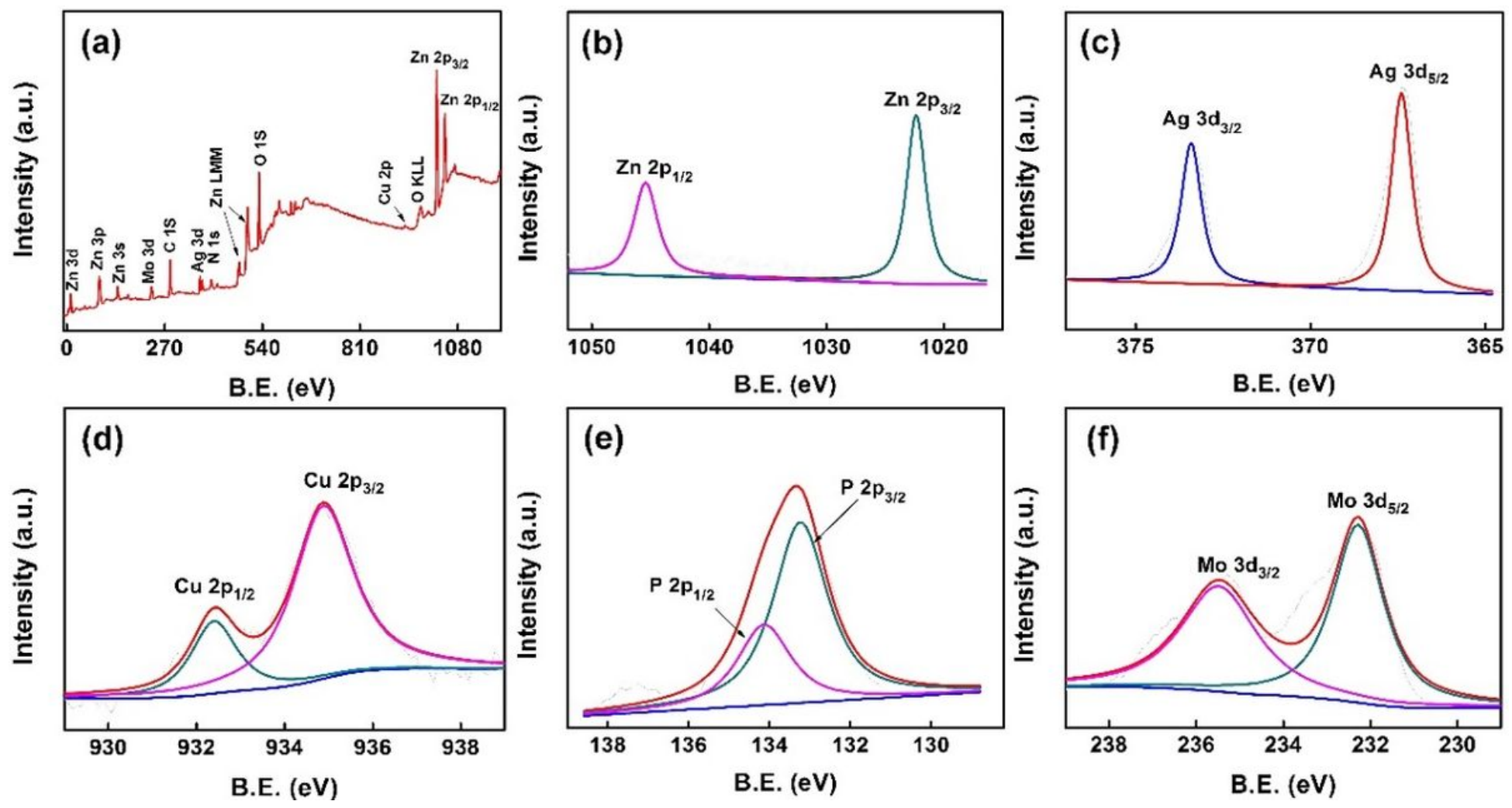

Figure 4

XPS spectra of AgZnO/POMs nanocomposites (a) full spectrum, (b) Zn 2p map, (c) Ag 3d map, (d) Cu 2p map, (e) P 2p map, (f) Mo 3d map. 


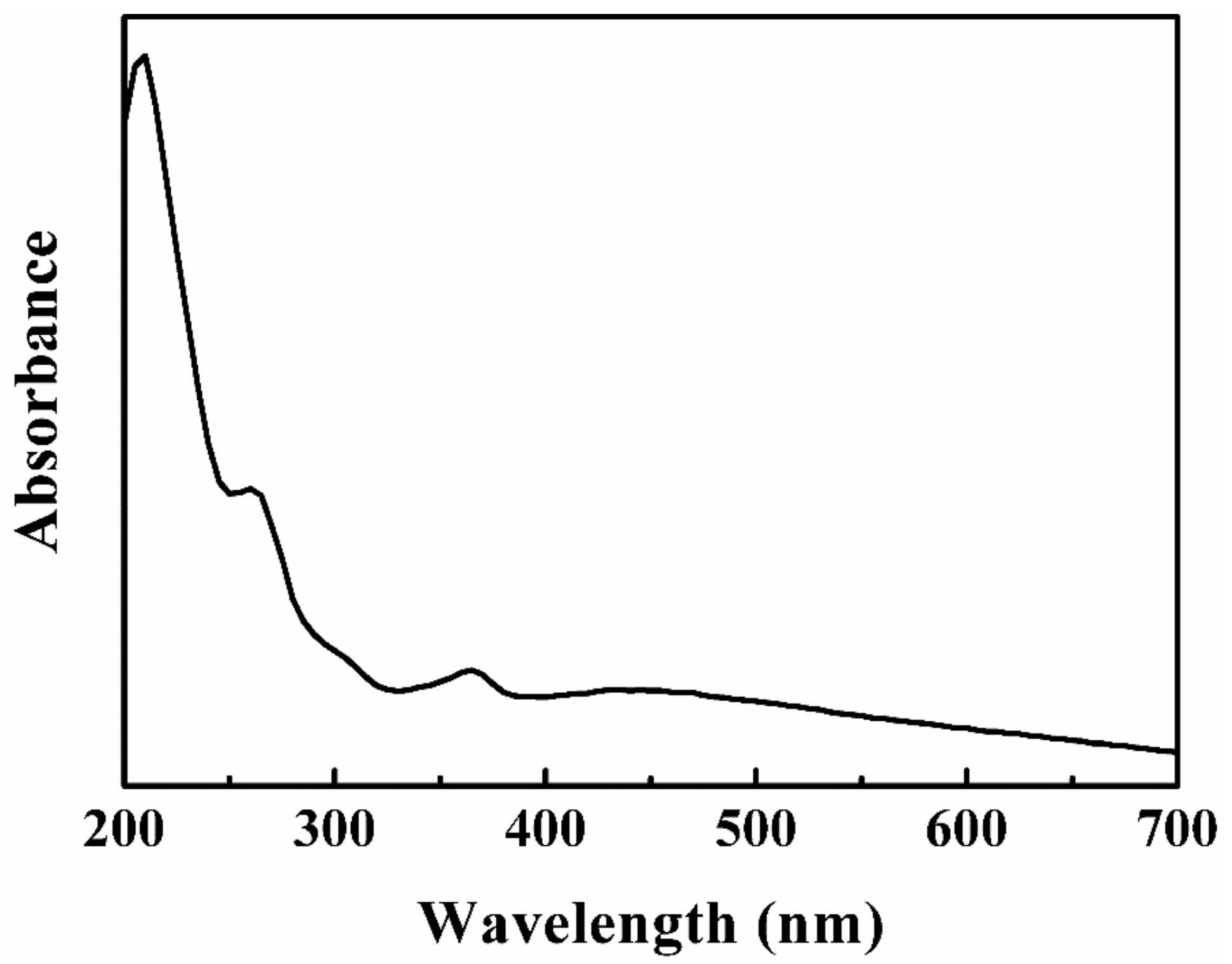

Figure 5

UV-vis absorption spectrum of photocatalytic-adsorbent AgZnO/POMs nanocomposites.
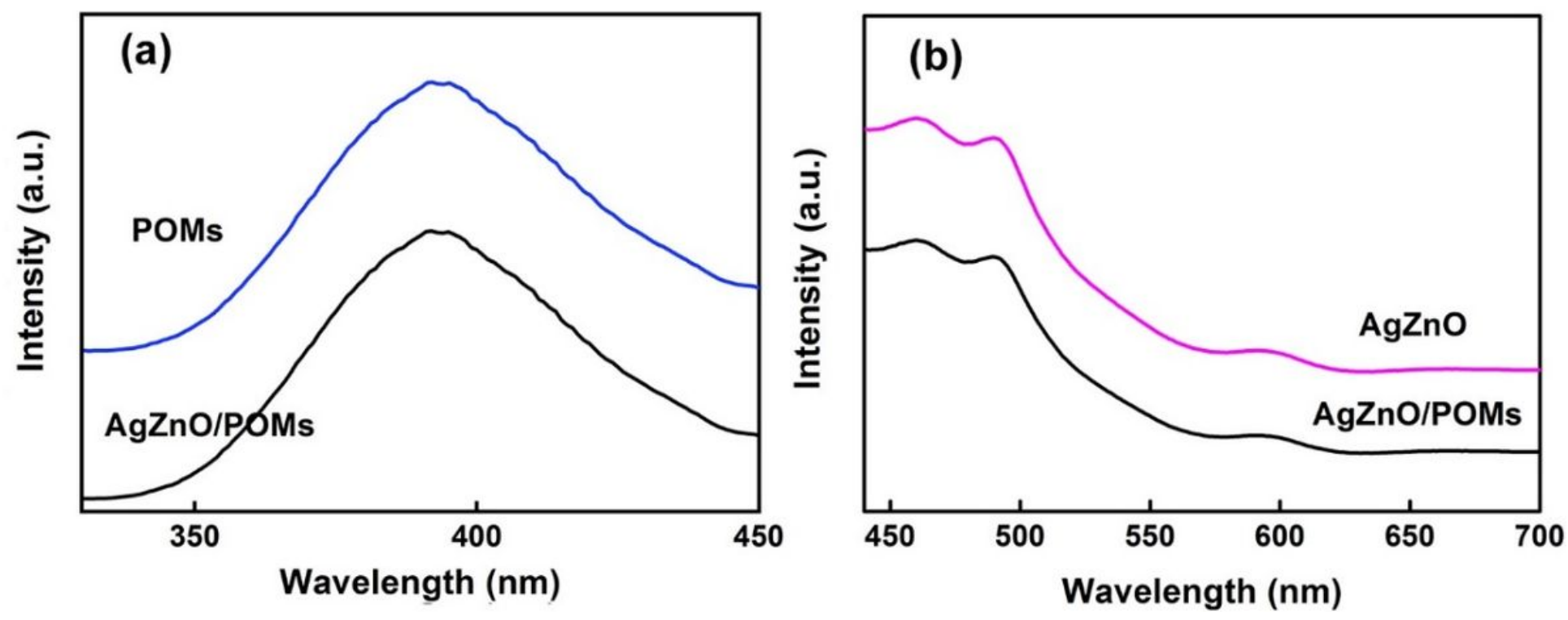
Figure 6

(a) Solid PL emission spectra of POMs and AgZnO/POMs with excitation wavelength $\lambda$ ex $=241 \mathrm{~nm}$, (b) Solid PL emission spectra of AgZnO and AgZnO/POMs with excitation wavelength $\lambda e x=380 \mathrm{~nm}$.
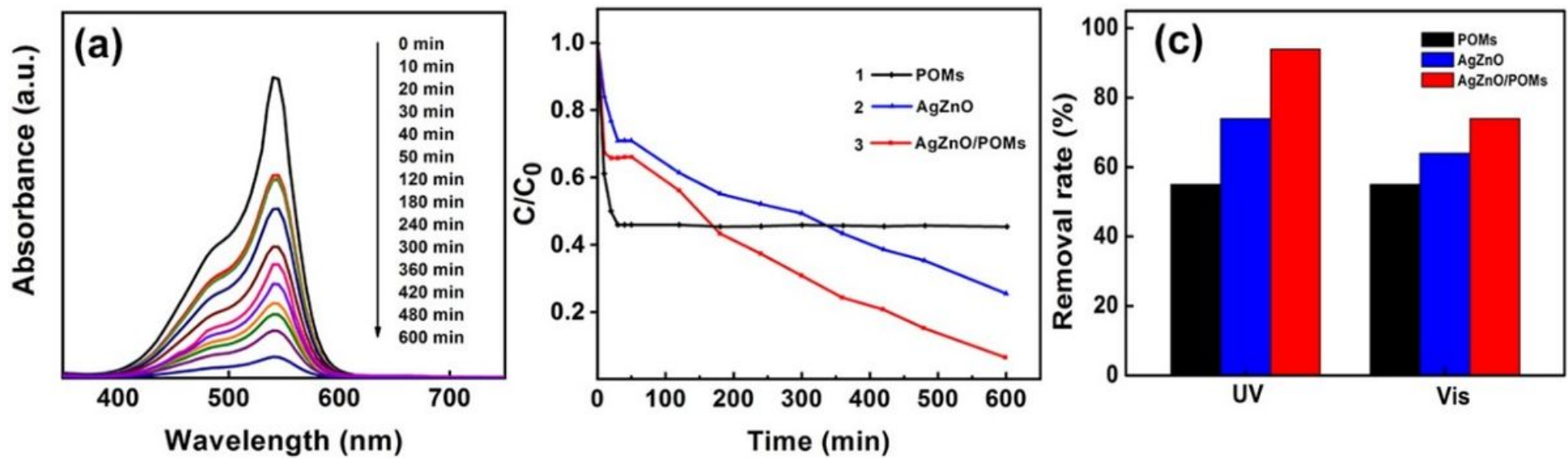

Figure 7

(a) UV-vis absorption spectra of BM solution containing the AgZnO/POMs nanocomposites, (b) Degradation curves of different materials for removing BM, curve: (1) POMs, (2) AgZnO (3) AgZnO/POMs nanocomposites, (c) Histogram of the removal of BM by POM, AgZnO and AgZnO/POMs nanocomposites under UV and Vis irradiation.
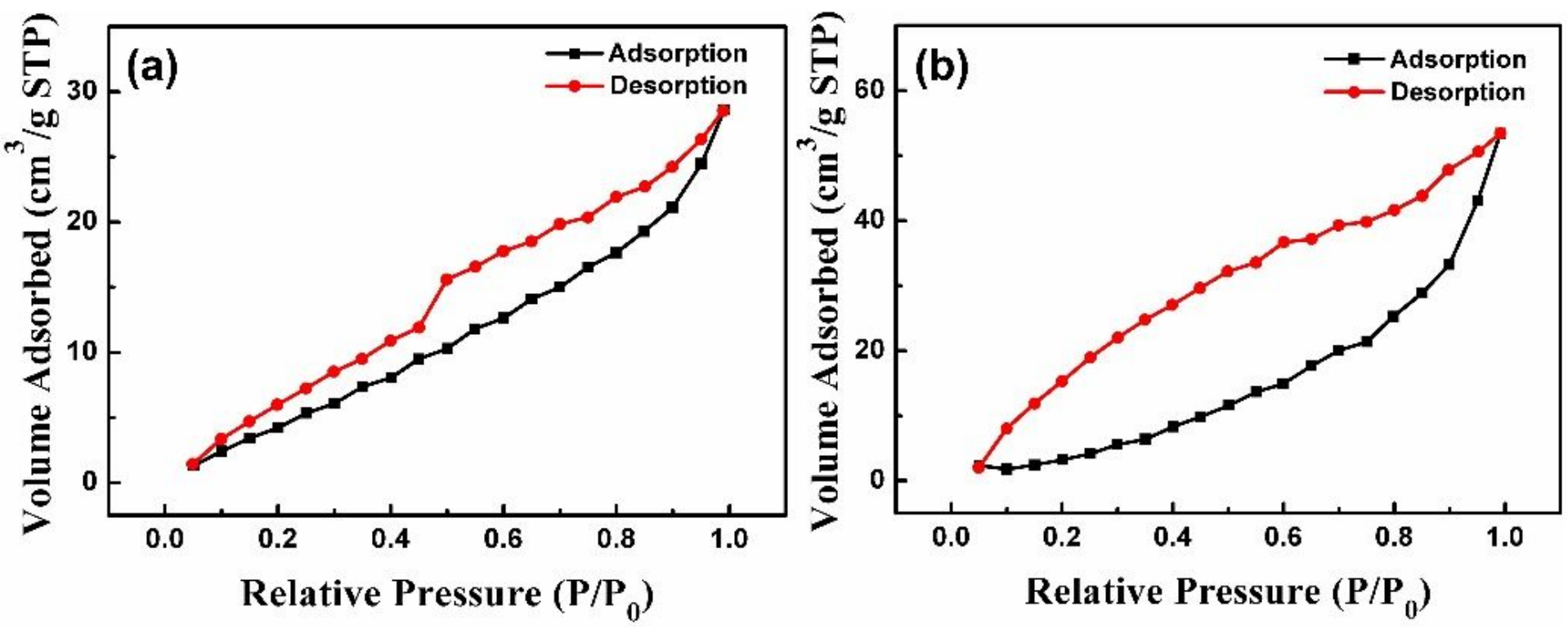

Figure 8

(a) N2 adsorption-desorption isotherm of AgZnO hybrid nanoparticles, (b) N2 adsorption-desorption isotherm of AgZnO/POMs nanocomposite. 

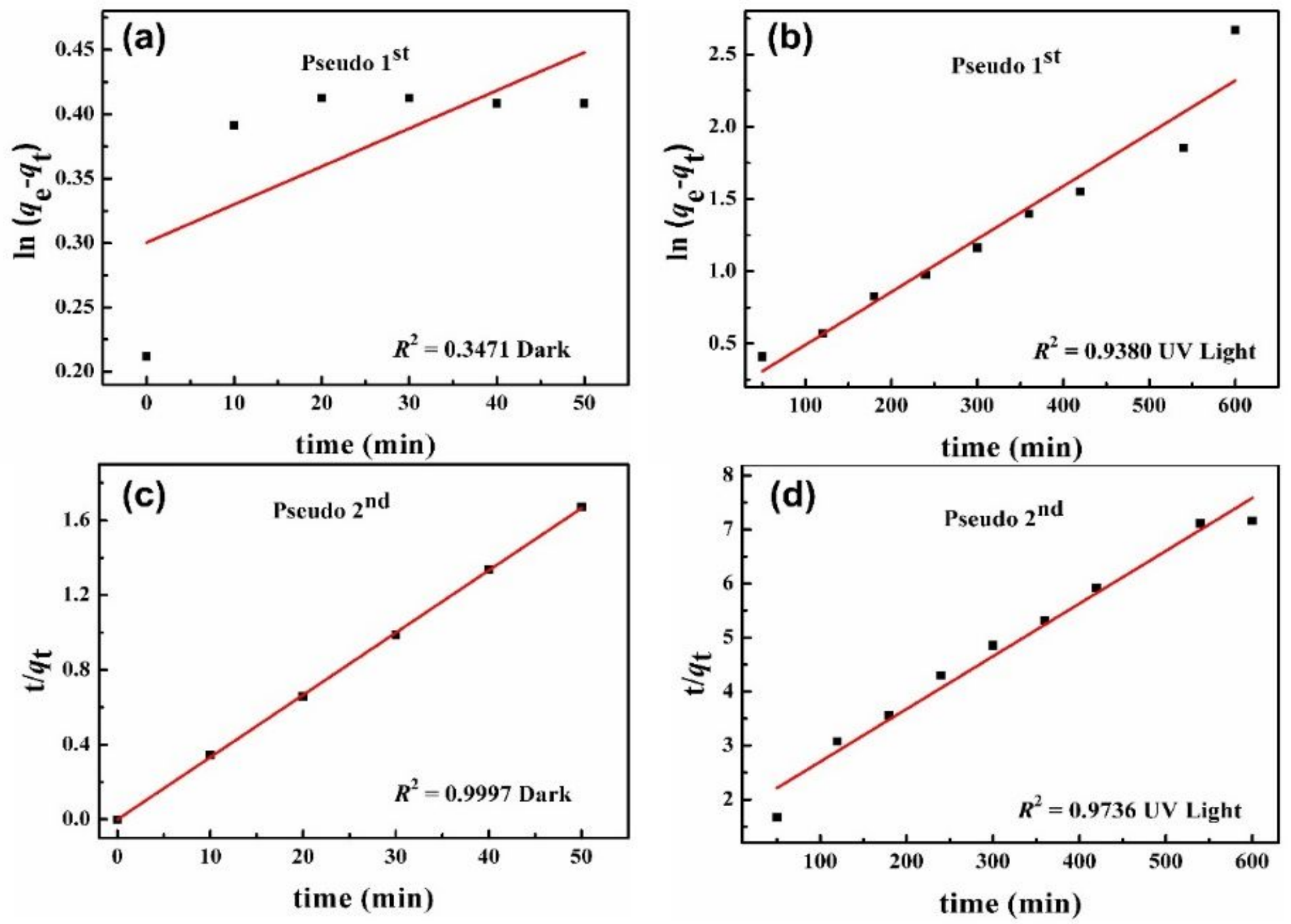

Figure 9

The kinetic plots for removing BM by AgZnO/POMs nanocomposites, (a) and (b) pseudo-first-order kinetics, (c) and (d) pseudo-second-order kinetics. 


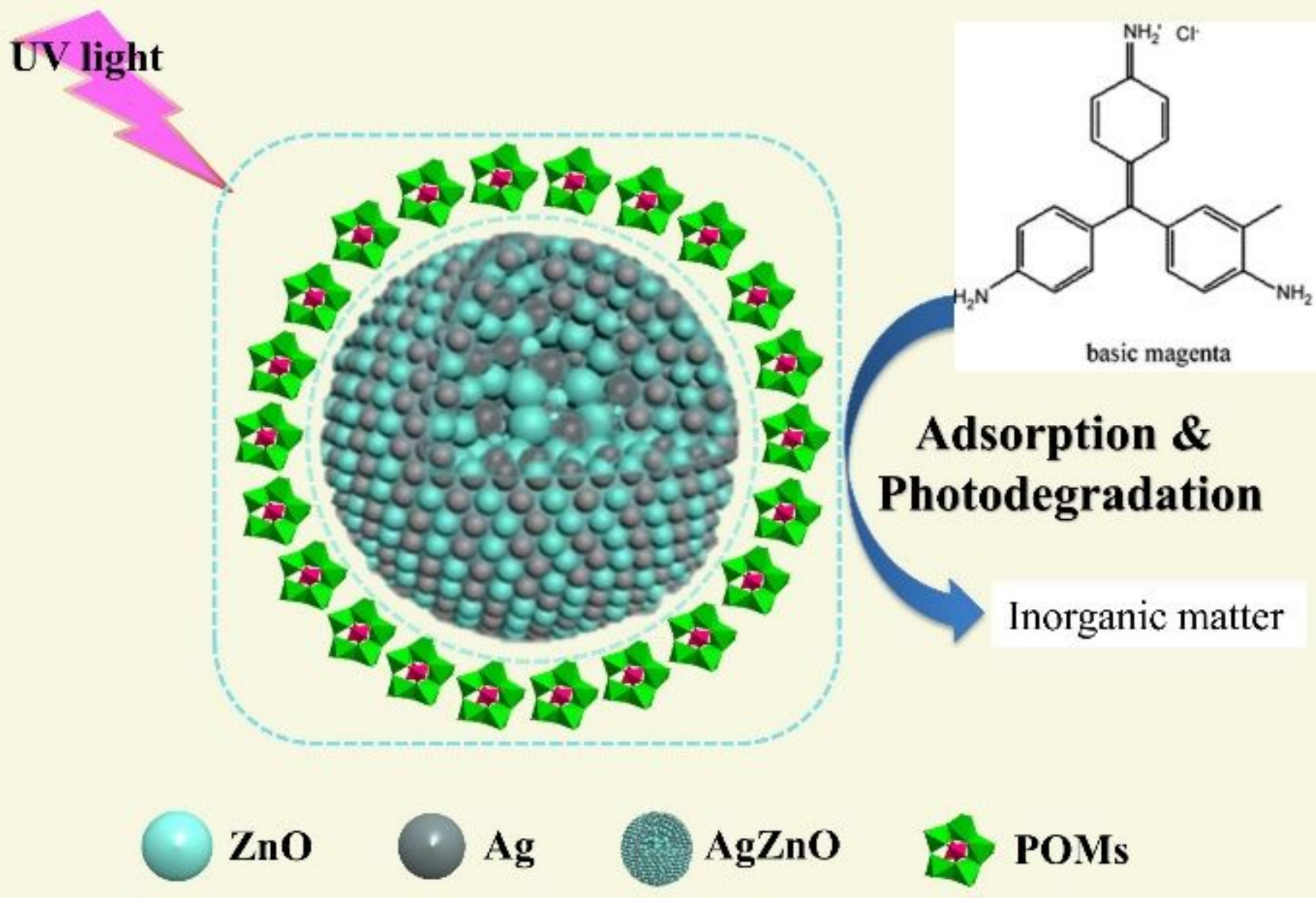

Figure 10

Schematic illustration of degradation of BM by AgZnO/POMs nanocomposites.
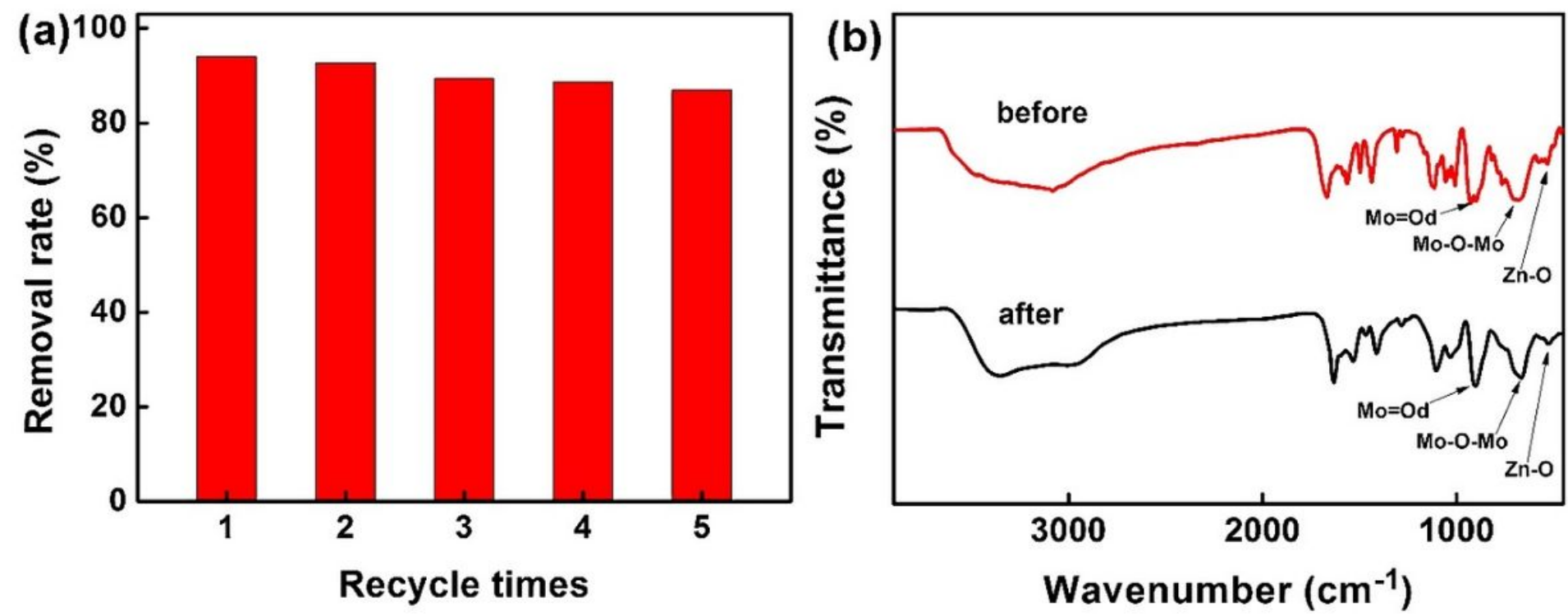

Figure 11

(a) Histogram of recycl removal BM for five cycles, (b) Comparison of FIRT spectra of AgZnO/POMs nanocomposites before and after five cycles. 


\section{Supplementary Files}

This is a list of supplementary files associated with this preprint. Click to download.

- floatimage1.jpeg 